\title{
The Impact of User Behaviours on the Socialisation Process in Enterprise Social Networks
}

Joschka Hüllmann

Department of Information Systems

University of Münster

Münster, Germany

Email: joschka.huellmann@uni-muenster.de

\section{Tobias Kroll}

Department of Computer Science and Applied Cognitive Science

University of Duisburg-Essen

Duisburg, Germany

Email: tobias.kroll@uni-due.de

\begin{abstract}
The success of teams in enterprise social networks (ESN) is of high importance in today's project-based and digitised work environments. In this context, onboarding of new hires or allocated team members means the adoption of group characteristics and behaviours. Studies identified cohesion and trust as part of the socialisation process and found communication behaviours that facilitate socialisation. ESN not only enable efficient communication or relationship building, they also make the socialisation processes visible and analysable. In this paper, we propose to use metrics from social network analysis (e.g. extraversion, openness and proactiveness) to operationalise communication behaviours identified as positive for socialisation. First evaluations with two ESN data sets in OLS, beta regression and multilevel models sparsely support the influence on closeness, which we expect to reflect the level of group integration.
\end{abstract}

Keywords Socialisation, Enterprise social networks, User behaviours 


\section{Introduction}

In the contemporary workplace, the formation of successful teams is a crucial challenge for management, as people increasingly change jobs and the rapid composition of dynamic project-based teams becomes the norm (Powell et al. 2004). Part of the challenge is the process of integrating new hires into existing teams, called socialisation or onboarding. Understanding and improving the outcomes of this process is an ongoing issue in practice and research alike (Bauer and Erdogan 2011). An effective onboarding process can increase the likeliness of new employees staying, whereas a poor process leads to a high fluctuation rate and losses for the organisation (Willyerd 2012).

Organisations employ different means of supporting the socialisation process, with enterprise social networks (ESN) being one of them (Gonzalez et al. 2013). ESN do not only provide a platform to support the process, but also make it visible: With increasing prevalence of ESN in organisations, a lot of communication data is generated, which has been used to analyse social relationships, social capital and to identify user behaviours in social networks (Stieglitz, Meske, et al. 2018; Wehner et al. 2017). Companies like Google have tried to identify patterns that distinguish effective from ineffective teams without success, but noticed the influence of individual and group behaviour may be relevant (Duhigg 2016). Bauer and Erdogan (2011) found behaviours of employees as antecedents among others that influence the socialisation process. Research on how the online user behaviours in ESN may elucidate the socialisation process is lacking. Thus, we address the research question "How do individual user behaviours of new hires in ESN communication affect their integration into different social groups?" in this paper. The study contributes a significant step to providing actionable insights for management that supports the crucial challenge of effective team formation by the means of social network analysis and prediction of how well new hires' behaviours fit to their team.

Our contribution builds on top of previous ESN literature. First, we study the literature on socialisation, ESN and user behaviours, with the aim to map the ESN user behaviours to the socialisations process' antecedents. From a review of 44 network metrics, we build hypotheses about their effect on successful socialisation outcomes. Regression analyses support only some assumptions about the effect, and require more data and in-depth analyses in the future. However, we understand this paper as an innovative approach and basis for further studies on the user behaviours in ESN. So far, this paper presents the underlying idea of the user behaviour's influence on socialisation from a quantitative social network analysis perspective.

\section{Background}

\subsection{Teams and Socialisation}

Teams are an important unit of organisations and nowadays organisations are quickly forming teams to respond to changes in the environment and to stay competitive (Bergiel et al. 2008; Duhigg 2016). To support teams, technology is essential as it enables communication and collaboration (Bergiel et al. 2008; Powell et al. 2004). Prerequisites of successful team communication and collaboration include the need to build shared norms and form a cohesive team (Maznevski and Chudoba 200o). During the formation of teams, early communication is a necessity to foster interpersonal relationships and to establish team cohesion (Maznevski and Chudoba 2000). When new hires join an existing team, their level of integration into the team is an outcome of the socialisation process (Powell et al. 2004). During the socialisation process, new hires must understand and adopt the behaviours of their team (Leidner et al. 2010). However, not every person fits in every team, hindering the socialisation process or making it impossible (Bergiel et al. 2008).

Organisational socialisation, or onboarding, is the process, in which new hires learn the knowledge, skills and behaviours of the organisation to fill their roles and responsibilities (Bauer and Erdogan 2011; Gonzalez et al. 2013; Saks and Ashforth 1997). A successful socialisation process leads to satisfied and productive employees, while poor socialisation leads to early departure or ineffectiveness of the new hires (Bauer and Erdogan 2011). However, reaching a successful socialisation process and respective outcomes is challenging (Gonzalez et al. 2013). Organisations employ programs, ideas, and other means to help this process, enterprise social network platforms being one of them (Gonzalez et al. 2013).

For the analysis of the socialisation process, Saks and Ashforth (1997) propose a multilevel process model, which has been well received and picked up by Bauer and Erdogan (2011) and Gonzalez et al. (2013). Part of this multilevel process model are the antecedents, which adjust the process and lead to different socialisation outcomes (Saks and Ashforth 1997). Bauer and Erdogan (2011) describe characteristics and behaviours of new employees as two of these antecedents. The characteristics of new 
hires that influence the process are a proactive personality, extraversion and openness. A proactive personality takes charge, asks questions, and controls the environment, both of which result in quick learning of the shared norms of the team and describe an information-seeking behaviour (Major et al. 2016; Bauer and Erdogan 2011). According to Kammeyer-Mueller and Wanberg (2003), people, who are open to new experiences and interpret them as opportunities rather than threats, learn from uncertain situations and appreciate feedback, which is linked to positive socialisation outcomes and feedbackseeking behaviour. Likewise, extraverts enjoy to get to know and socialise with their new colleagues, improving the integration early on by their relationship-building behaviour (Bauer and Erdogan 2011). The outcomes of the socialisation model by Saks and Ashforth (1997) are role conformity on the individual level and strong cohesion on the group level, leading to a stable membership, higher effectiveness and a strong group culture. Especially the group outcomes have also been researched and identified as outcomes of continuous enterprise social network use (Riemer, Finke, et al. 2015), making enterprise social networks a phenomenon linked to the socialisation process and a suitable media to further investigate the socialisation process in modern teams, which make extensive use of such tools (Chui et al. 2012).

\subsection{Enterprise Social Networks to Support Socialisation}

Enterprise social networks (ESN) have been described as a consumerised social network platform deployed within organisational boundaries, offering a previously separated set of communication tools (Ellison et al. 2015). ESN platforms facilitate social processes and activities (Berger et al. 2014). They support collaboration, communication, knowledge sharing and connect people (Riemer, Stieglitz, et al. 2015). Users seek information, find experts, solve problems together, share opinions or discuss work and ideas (Berger et al. 2014; Mäntymäki and Riemer 2016; Richter and Riemer 2013). They further enhance innovation (Kuegler et al. 2015) and productivity (Aboelmaged 2018). Research found that ESN create social capital (Riemer, Finke, et al. 2015), which is described to influence mutual trust, shared norms and values, as well as cohesion (Nahapiet and Ghoshal 1998). It is also associated with a shared culture, language, increased knowledge and effectiveness (Oh et al. 2004).

Gonzalez et al. (2013) try to understand how exactly enterprise social networks support the socialisation process. They analyse how enterprise social media use and patterns of interactions are associated with the outcomes of the socialisation process. They found that ESN usage affects the social acceptance and group-integration of new hires and can speed up the socialisation process. Furthermore, new hires strengthen their social connections with ESN usage and feel connected to others (Leidner et al. 2010), which leads to higher levels of trust (Leon et al. 2017).

ESN are a duality in that they not only mediate socialisation processes, but also make them visible. We can use ESN data to understand the socialisation process in the organisation and how new hires build their relationships. Since the integration of new hires or new project members into teams is challenging (Gonzalez et al. 2013), we explore the use of network data to inform staffing decisions.

\subsection{User Behaviours}

People differ in their communication behaviour, which is characteristic for different types of users (Cetto et al. 2018; Stieglitz, Mirbabaie, et al. 2018). Distinct behaviours can be found in public social networks and enterprise social networks (Leon et al. 2017). Previous research has identified user behaviours with the aim of understanding the user composition of healthy (Angeletou et al. 2011) or effective social networks (Berger et al. 2014). For the identification of user behaviours, there is (1) a qualitative approach with interviews or content analyses, and (2) a quantitative approach by means of cluster or factor analysis of enterprise social network structure.

Following the latter, user behaviours are inferred from a user's distinct position, structural properties and from his activity patterns and contribution frequencies in the network (Angeletou et al. 2011; Gleave et al. 2009), to describe their distinct kinds of meta-communication (Hacker et al. 2017; Smith et al. 2009). We link the user behaviour metrics from ESN analysis to the user behaviours in the socialisation model, mentioned by Bauer and Erdogan (2011) and Saks and Ashforth (1997), to analyse how user behaviours, which can be inferred from ESN data, affect the socialisation process and the team integration. Besides using main contributions of the ESN community at recent IS conferences, we searched SCOPUS and Web of Science with the terms "user (behavio(u)r | role | dimension | metric | measure)", followed by one round of forward and backward search to identify 44 different user behaviours in the literature. We map the identified ESN user behaviours to the three behaviours and three related personality traits of Bauer and Erdogan (2011) based on the authors' descriptions (Table 1). The descriptions and calculation schemas are similar in the literature and overlap between different studies. Because Smith et al. (2009) provide early calculation schemas, we use them as the base and 
adapt them, if another schema is more dominant in the literature. We added the activity metric because it is relevant for investigating the effect of ESN use itself. Detailed arguments for each of the published metrics do not fit into the scope of this work.

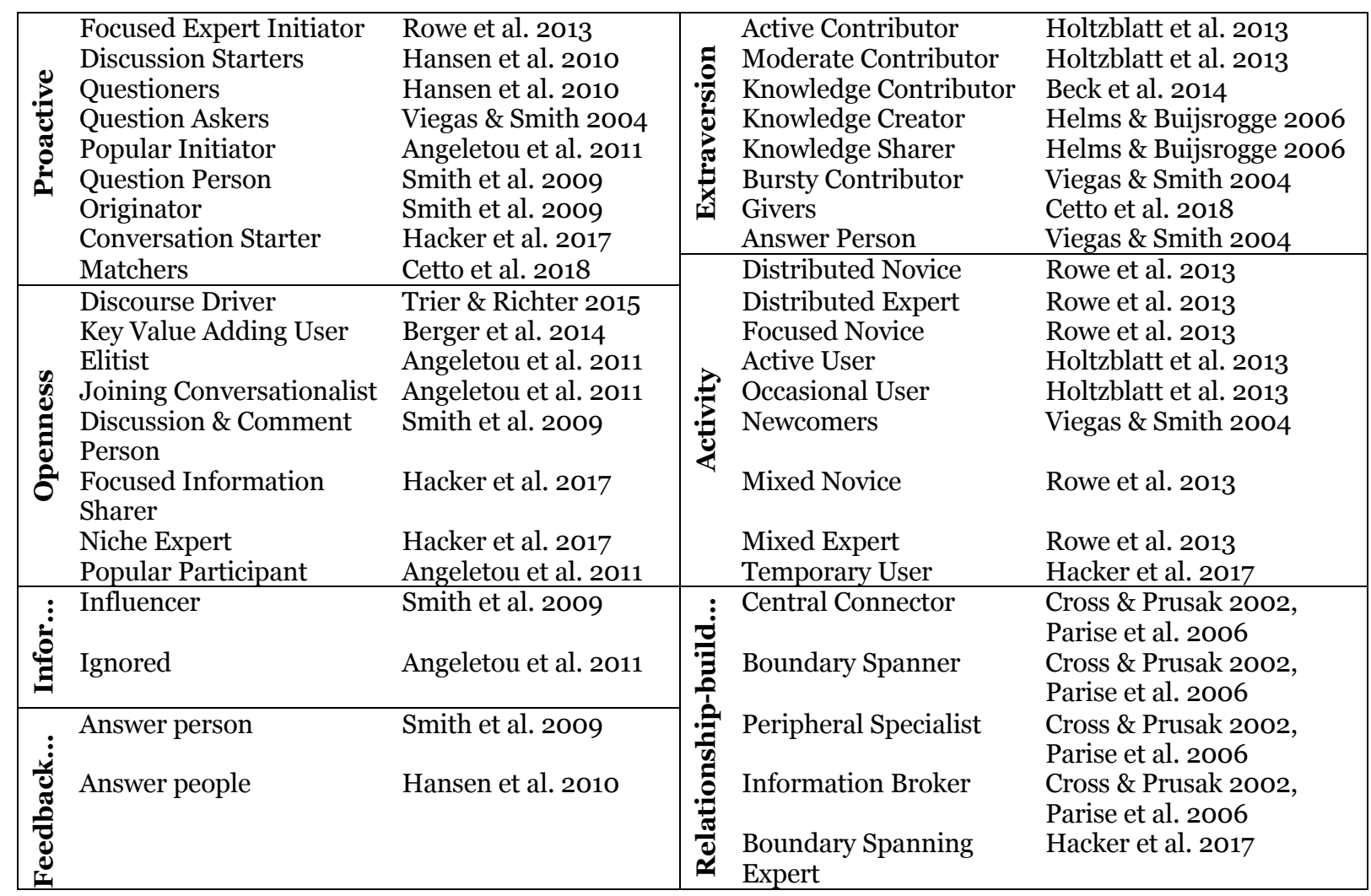

Table 1. Mapped metrics (Inform = Information-seeking, Relationship-build = Relationship-building, Feedback = Feedback-seeking) .

\section{Research Design}

In our study design, we describe the socialisation process model as linear relationships between the antecedent behaviours and the resulting outcomes, e.g. more extraversion, openness or relationships lead to better outcomes. We operationalise the behaviours of Bauer and Erdogan (2011) using network metrics and predict the fit between employee and team. We hypothesise that all seven behaviour metrics, illustrated in Table 2, have a simple positive impact on the outcomes of the socialisation process of a given person.

\begin{tabular}{|c|c|c|}
\hline Name & Formal representation & Reasoning \\
\hline Proactive & $\frac{(\text { Initiated Threads) }}{\text { (Total participated Threads) }}$ & $\begin{array}{l}\text { More open conversations, asking questions } \rightarrow \\
\text { faster learning }\end{array}$ \\
\hline Openness & $1-\frac{(\text { Total participated Threads) }}{(\text { Total Interactions })}$ & $\begin{array}{c}\text { More openness to new people and experiences } \rightarrow \\
\text { quicker social integration }\end{array}$ \\
\hline Information ... & (Authors received from) & Information-seeking $\rightarrow$ faster learning \\
\hline Extraversion & (Authors sent to) & Likes to talk to people $\rightarrow$ social integration \\
\hline Feedback... & $\frac{(\text { Likes received })+(\text { Mentions received })}{(\text { Posts written })}$ & $\begin{array}{l}\text { Receives feedback on posts } \\
\rightarrow \text { better learning }\end{array}$ \\
\hline Relationship ... & mean(Neighbors'Degrees) & Knows people before $\rightarrow$ social integration \\
\hline Activity & $\frac{(\text { Days with Post })}{(\text { Last Visit })-(\text { First Visit })}$ & Activity $\rightarrow$ prerequisite for integration \\
\hline
\end{tabular}

Table 2. Behaviour Metrics and Reasoning for Inclusion (adapted from Smith et al. 2009). 
Proactiveness describes the number of conversations a user has started, compared to his overall number of posts. According to Hacker et al. (2017), Hansen et al. (2010) and Smith et al. (2009), a high number of initiated threads indicates an information-seeking person or a conversation starter. This behaviour is associated to successful socialisation outcomes, because it can lead to faster learning of the new hire (Bauer and Erdogan 2011). Openness describes how many posts a user contributes in each conversation on average. A high value indicates an engager, who aims at focused reciprocal interactions (Angeletou et al. 2011; Trier and Richter 2015). Since such interactions strengthen social relationships, they lead to increased social integration Information-seeking describes how many replies a user has received from others in response to his information requests, which indicates how accepted the user is by other team members and how much information he may receive (Gonzalez et al. 2013), which contributes to his learning. Extraversion describes how many replies a user has written to others. A high value indicates a user, who engages broadly across the network (Holtzblatt et al. 2013). This behaviour is associated to successful socialisation outcomes, as the user gets to know a other people (Bauer and Erdogan 2011). Feedback-seeking describes how many likes and mentions a used receives per post, which shows the feedback a user receives from the contributions to the network (Angeletou et al. 2011; Smith et al. 2009), which indicates his learning behaviour and positively influences his socialisation. Relationship-building describes how well a user relates to other people in the network via his neighbours. A high value indicates that the user is part of a cohesive team (Bergiel et al. 2008; Riemer, Finke, et al. 2015), which has a positive influence on socialisation outcomes as it improves the social integration. Activity quantifies the regular activity of a user. As maintaining social relationships is essential for successful teams (Kammeyer-Mueller and Wanberg 2003), activity is crucial for successful integration.

We focus on the strong cohesion outcome of the socialisation model (Saks and Ashforth 1997) and operationalise group integration as the average closeness of the user to the other members of the team. It captures the relationships the user formed with other team members and how the user is embedded into the team structure.

\subsection{Data Collection}

To determine how user behaviours influence the socialisation process in ESN, we had access to two data sets on the meta-communication of two financial institutes $(4,500$ and 32,500 employees) based in Australia, both running an ESN platform. The data sets contain all interactions ever made on the platforms, with each interaction being either a post, reply, like or mention. For each interaction the author, the recipient, the thread, the group (team in formal hierarchy) and the time is stored. All data sets span the period from 2010 until the end of 2016 and vary in size. The first one covers 168,706 interactions from 4,125 accounts and the second one covers 233,444 interactions from 12,017 accounts. A small excerpt of the data is shown in Table 3. From the data, a social network graph is constructed, so that each interaction represents an edge from the author to the recipient - author and recipient being represented by vertices. For each user we calculate the user behaviour metrics using the network graph. Based on the metrics, we fit an OLS regression, a beta regression model and a mixed model to identify what effects the user behaviours have on the socialisation outcomes.

To not distort the analysis results, we cleanse the data set from inactive users and groups. Users and groups with less than 50 interactions per year, roughly 1 per week, are excluded from the analysis. Three (potentially technical) users with very high number of interactions are removed, groups are filtered to have a minimum size of five members and each member must be part of the group for at least three days.

\begin{tabular}{|l|l|l|l|l|l|l|}
\hline id & source & target & groupid & threadid & datetime & class \\
\hline 124 & 1775662 & 1810074 & 78023 & 51876215 & 2010-07-04 09:22:24 & Reply \\
\hline 125 & 1775662 & 1858829 & 78023 & 52045895 & 2010-07-09 11:25:53 & Like \\
\hline 126 & 1775662 & 1858829 & 78023 & 52349096 & 2010-07-06 00:49:56 & Reply \\
\hline
\end{tabular}

Table 3. Excerpt of Data Set.

We cross all users and groups and split the network into two subnetworks for each pair. The first subnetwork describes the user's position and focal structure outside of the group, while the second subnetwork describes the user's position and the structure within the group. As the user behaviour is inherent to the user, we calculate the behaviour metrics (independent variables) from the user's interactions and position over the whole network, excluding the paired group. The level of integration (dependent variable) is determined for each pair of user and group, using the within structure of the paired group to measure the integration. The overall structure describes the behaviour inherent to the 
user on average, while the within structure describes the user's particular behaviour and integration in the paired group. The $\mathrm{R}$ code of the pre-processing and analysis is available for replication.

\subsection{Regression Analysis}

To identify how the behaviour metrics affect the group integration, we perform a linear regression analysis. From the spearman correlation matrix of the variables (c.f. Table 4), we determine a high correlation between the closeness and the size of a group, as the social network gets sparser with increasing size, as well as between extraversion and activity. As a result, and similar to other studies (e.g. Oh et al. 2004), we control for the size of the group in the regression. Since the number of days a user is a member of a group influences his ability to interact with others and integrate, we add this metric as the second control variable.

\begin{tabular}{|c|c|c|c|c|c|c|c|c|c|}
\hline Set 1 & INT & PRO & OPE & INF & EXT & REL & ACT & FEE & GRO \\
\hline PRO & $0.06^{* * * *}$ & & & & & & & & \\
\hline OPE & 0.02 & $-0.17^{* * *}$ & & & & & & & \\
\hline INF & -0.01 & $-0.22^{* * * *}$ & $0.27^{* * * *}$ & & & & & & \\
\hline EXT & $-0.06^{* * * *}$ & $-0.11^{* * * *}$ & $0.23^{* * * *}$ & $0.56^{* * * *}$ & & & & & \\
\hline REL & $-0.14^{* * * *}$ & $-0.17^{* * * *}$ & $-0.06^{* * * *}$ & 0.01 & $0.06^{* * * *}$ & & & & \\
\hline ACT & -0.02 & $0.10^{* * *}$ & $-0.03^{* *}$ & $0.33^{* * * *}$ & $0.64^{* * * *}$ & $-0.04^{* * *}$ & & & \\
\hline FEE & 0.01 & $0.23^{* * * *}$ & $0.10^{* * *}$ & $0.35^{* * *}$ & 0.01 & $-0.07^{* * *}$ & $0.05^{* * *}$ & & \\
\hline GRO & $-0.98^{* * * *}$ & $-0.08^{* * * *}$ & -0.01 & 0.02 & $0.06^{* * * *}$ & $0.14^{* * * *}$ & 0.01 & -0.01 & \\
\hline DAY & $-0.09^{* * * *}$ & $-0.06^{* * * *}$ & -0.02 & $0.07^{* * * *}$ & 0.04 & -0.02 & $-0.06^{* * *}$ & -0.01 & $0.13^{* * * *}$ \\
\hline Set 2 & INT & PRO & OPE & INF & EXT & REL & $\mathrm{ACT}$ & FEE & GRO \\
\hline PRO & $-0.07^{* * *}$ & & & & & & & & \\
\hline OPE & $-0.06^{* * * *}$ & $0.05^{* *}$ & & & & & & & \\
\hline INF & $-0.05^{* * *}$ & $-0.25^{* * * *}$ & $0.24^{* * * *}$ & & & & & & \\
\hline EXT & $-0.07^{* * * *}$ & $-0.10^{* * * *}$ & $0.03^{*}$ & $0.62^{* * *}$ & & & & & \\
\hline REL & $-0.1^{* * * *}$ & $-0.24^{* * * *}$ & $-0.04^{* * *}$ & $0.16^{* *-*}$ & $0.26^{* * * *}$ & & & & \\
\hline $\mathrm{ACT}$ & 0.03 & 0.01 & $-0.16^{* * * *}$ & $0.15^{* * *}$ & $0.39^{* * *}$ & -0.01 & & & \\
\hline FEE & $-0.14^{* * * *}$ & $0.43^{* * * *}$ & $0.32^{* * * *}$ & $0.36^{* * * *}$ & $0.05^{* * * *}$ & $-0.06^{* * * *}$ & $-0.14^{* * *}$ & & \\
\hline GRO & $-0.97^{* * *}$ & $0.09^{* * * *}$ & $0.07^{* * * *}$ & $0.04^{* * *}$ & $0.05^{* * *}$ & $0.07^{* * * *}$ & $-0.04^{* *}$ & $0.17^{* * * *}$ & \\
\hline DAY & $-0.16 * * *$ & 0.01 & $-0.07^{* * * *}$ & $0.07^{* * *}$ & $0.08^{* * * *}$ & -0.02 & $-0.06^{* * * *}$ & 0.01 & $0.21^{* * * *}$ \\
\hline
\end{tabular}

Table 4. Correlation matrix for both data sets (abbreviations are first three letters of variables).

As social networks tend to be sparse - in particular bigger networks - the distribution of the closeness variable is highly skewed. Most people have a very low closeness value, while there are only a few with a high value (c.f. Table 5). To reduce the skewness, we take the log-transformation for the closeness variable. We have also tested square and square-root transformation, both of which led to consistent results. Even after the log-transformation, the distribution of closeness is skewed. To deal with the skewness, we compare the results of the OLS regression with the results of beta regression (Ferrari and Cribari-Neto 2004), which is suitable for modelling rates and proportions and does not require residuals to be normal distributed, but beta distributed instead. To consider group heterogeneous effects, we also compare the results with a mixed model, computing random intercepts per group. The calculations were performed with lm4 v1.1.17 (Bates et al. 2015) and betareg v3.1.o (Cribari-Neto and Zeileis 2009).

\section{Results}

After filtering the data, 4,696 observations of user/group pairs (data set 1), or 3,121 observations (data set 2) respectively, are used to fit the model (c.f. Table 5). The signs of the coefficients are consistent, except for the variables connectedness, size and days (c.f. Table 6). For connectedness, the OLS regression of data set 1 shows a positive value, compared to the other three results. For size and days, the beta regression shows the opposite sign. The differences are tolerable due to their small effect. We find varying significance levels in both datasets with the beta regression results supporting the respective OLS regression results, albeit showing higher p-values. Counterintuitively, outgoingness and connectedness are negatively associated with the group integration. Receiving likes and mentions does not lead to a positive effect on the group integration. The results on initiation and verbosity are non- 
conclusive. While the OLS regression on data set 1 shows a significant positive effect, the result is not substantiated by the other results. The group size significantly affects the integration into the group. As the values are not significant, no statement can be made about the activity or the number of days a user is a member of the group.

\begin{tabular}{|l|l|l|l|l|l|l|l|l|l|l|l|}
\cline { 2 - 12 } \multicolumn{1}{l|}{ Data set 1 } & \multicolumn{1}{l|}{ Data set 2 } \\
\hline Statistic & $\mathrm{N}$ & Mean & St. Dev. & Min & Max & N & Mean & St. Dev. & Min & Max \\
\hline INT & 4,696 & 0.002 & 0.010 & $\mathrm{o}$ & 0.150 & 3,121 & 0.003 & 0.010 & o & 0.145 \\
\hline PRO & 4,703 & 0.690 & 0.177 & 0.042 & 1000 & 3,177 & 0.770 & 0.160 & 0.184 & 1000 \\
\hline OPE & 4,703 & 0.357 & 0.128 & 0.015 & 0.941 & 3,177 & 0.335 & 0.152 & 0.000 & 0.904 \\
\hline INF & 4,703 & 47663 & 32505 & o & 229 & 3,177 & 64998 & 44892 & 3 & 291 \\
\hline EXT & 4,703 & 61145 & 32380 & 1 & 188 & 3,177 & 71977 & 38846 & 1 & 215 \\
\hline REL & 4,702 & 116887 & 14172 & 7000 & 166312 & 3,177 & 150996 & 20921 & 59750 & 253333 \\
\hline ACT & 4,703 & 0.130 & 0.084 & 0.014 & 0.909 & 3,177 & 0.099 & 0.087 & 0.005 & 2000 \\
\hline FEE & 4,703 & 1013 & 0.854 & 0 & 10667 & 3,177 & 2300 & 1593 & 0.008 & 14071 \\
\hline DAY & 4,696 & 213557 & 178561 & 3 & 1,49 & 3,121 & 256648 & 289778 & 3 & 1,917 \\
\hline GRO & 4,696 & 234898 & 204466 & 6 & 766 & 3,121 & 239576 & 209458 & 7 & 818 \\
\hline
\end{tabular}

Table 5. Descriptive Statistics.

\subsection{Robustness}

Since both the independent and the dependent metrics are calculated from the same data source, the simultaneity bias is relevant. We account for this by partitioning the data as described before, so that the behaviour metrics are calculated over the whole data set, while the integration metrics are calculated from the subnetworks of each group. To test for the simultaneity-bias, we checked the Spearman correlations, which are in the norm. Only the control variables are correlated with the independent variable, but not the independent variables $(\rho<0.15)$. We conducted the Durbin-Watson test, which showed no autocorrelation $(\mathrm{d}=2, \mathrm{p}<0.05)$ and checked for multicollinearity in the dependent variables using condition indices $(<0.2)$ and variance inflation factors $(<2$, except outgoing). The residuals are approximately normal distributed, except for a minor right tail due to the skewed distribution of the closeness values. The Breusch-Pagan showed heteroscedasticity $(\mathrm{p}<0.01)$, although it is quite unreliable for not perfectly normal residuals. Therefore, we calculated heteroscedastic robust standard errors, which lead to consistent results. To test the result, we used the beta regression model, which does not assume normality in the residuals. The signs of the coefficients are unchanged. However, the significance in the beta regression results is lower than in the OLS model. We ran both analyses on two different data sets of different size from different organisations, both of which showed similar results. While the results are moderately robust between OLS and beta regression, considering group heterogeneous effects changes the result, indicating that the effects, as measured with the behaviour metrics, may not be simply linear as hypothesised; testing random slopes did not improve the results. Lacking better data on group level and media level, as well as only having meta-communication data and no information on what actual text and content the interactions convey, leads to improvable robustness of the statistical model. Interpretation of how the ESN user behaviours from the literature measure the antecedents of Bauer and Erdogan (2011) and predict the socialisation outcomes should be very cautious. Nevertheless, this check of viability, to work only with meta-information, is one of this study's goals and contributions to our discipline.

\section{Discussion}

Our results are preliminary as we plan to dive deeper into the relationship between user behaviours and group types, i.e. we want to include data on the groups in our analysis, because user behaviours apparently have different effects depending on the group a user is assigned to. Nevertheless, these results provide first insights, if and how ESN user behaviours can be used to determine the socialisation outcomes of new hires.

Extraversion is - in contrast to our hypothesis - negatively associated with socialisation outcomes in our models. Holtzblatt et al. (2013) describe an extravert user as active in many groups, who enjoys a broad network of social relationships. However, they state that social relationships are not strengthened which may explain the opposite association. Others argue that such users contribute new knowledge and respond to many others (Cetto et al. 2018; Viégas and Smith 2004). For the group integration, cohesion 
and building trust via maintenance of strong relationships are important (Kammeyer-Mueller and Wanberg 2003; Saks and Ashforth 1997), which is not supported by broad (extraverted) communication, but rather focused communication.

\begin{tabular}{|c|c|c|c|c|c|c|}
\hline & \multicolumn{3}{|c|}{ Data set 1} & \multicolumn{3}{|c|}{ Data set 2} \\
\hline & $O L S$ & beta & mixed-effects & $O L S$ & beta & mixed-effects \\
\hline Proactiveness & \begin{tabular}{|l|}
0.133 \\
$(0.107)$
\end{tabular} & $\begin{array}{l}0.127 \\
(0.089) \\
\end{array}$ & $\begin{array}{l}-0.008 \\
(0.011) \\
\end{array}$ & \begin{tabular}{|l|}
0.045 \\
$(0.190)$
\end{tabular} & $\begin{array}{l}0.007 \\
(0.139)\end{array}$ & $\begin{array}{l}0.025^{* * *} \\
(0.013)\end{array}$ \\
\hline Openness & \begin{tabular}{|l}
$0.720^{* * * *}$ \\
$(0.143)$
\end{tabular} & $\begin{array}{l}0.231^{*} \\
(0.120)\end{array}$ & $\begin{array}{l}0.035^{* * *} \\
(0.014)\end{array}$ & \begin{tabular}{|l|}
0.229 \\
$(0.171)$
\end{tabular} & \begin{tabular}{|l|}
0.016 \\
$(0.125)$
\end{tabular} & \begin{tabular}{|l|}
0.011 \\
$(0.011)$
\end{tabular} \\
\hline Information-seeking & \begin{tabular}{|l}
$\begin{array}{l}0.003^{* * * *} \\
(0.001)\end{array}$ \\
\end{tabular} & \begin{tabular}{|l|}
$0.048^{* *}$ \\
$(0.024)$
\end{tabular} & $\begin{array}{l}-0.0003^{* * * *} \\
(0.0001)\end{array}$ & \begin{tabular}{|l|}
$\begin{array}{l}0.001 \\
(0.001)\end{array}$ \\
\end{tabular} & \begin{tabular}{|l|l|}
$\begin{array}{l}0.050 \\
(0.038)\end{array}$ \\
\end{tabular} & \begin{tabular}{|l|}
-0.0001 \\
$(0.0001)$ \\
\end{tabular} \\
\hline Extraversion & $\begin{array}{l}-0.003^{* * * *} \\
(0.001) \\
\end{array}$ & $\begin{array}{l}-0.092^{* * *} \\
(0.038)\end{array}$ & $\begin{array}{l}0.0002^{* * * *} \\
(0.0001)\end{array}$ & $\begin{array}{l}-0.004^{* * * *} \\
(0.001)\end{array}$ & $\begin{array}{l}-0.120^{* * * *} \\
(0.044)\end{array}$ & $\begin{array}{l}0.0001 \\
\text { (0.0001) }\end{array}$ \\
\hline Relationship-building & \begin{tabular}{|l|}
0.001 \\
$(0.001)$
\end{tabular} & $\begin{array}{l}-0.001 \\
(0.001) \\
\end{array}$ & \begin{tabular}{|l|l|}
0.0002 \\
$(0.0001)$
\end{tabular} & \begin{tabular}{|l}
$-0.005^{* * *}$ \\
$(0.001)$
\end{tabular} & \begin{tabular}{|l}
$-0.002^{* * * *}$ \\
$(0.001)$ \\
\end{tabular} & $\begin{array}{l}0.0001 \\
(0.0001) \\
\end{array}$ \\
\hline Activity & $\begin{array}{l}-0.056 \\
(0.264) \\
\end{array}$ & \begin{tabular}{|l|}
0.029 \\
$(0.207)$
\end{tabular} & $\begin{array}{l}0.044^{*} \\
(0.027)\end{array}$ & $\begin{array}{c}-0.224 \\
(0.315)\end{array}$ & $\begin{array}{l}0.111 \\
(0.228) \\
\end{array}$ & $\begin{array}{l}0.018 \\
(0.020)\end{array}$ \\
\hline Feedback-seeking & $\begin{array}{l}-0.045^{*} \\
(0.023) \\
\end{array}$ & $\begin{array}{l}-0.024 \\
(0.019) \\
\end{array}$ & $\begin{array}{l}0.003 \\
(0.002)\end{array}$ & \begin{tabular}{|l}
$-0.067^{* * *}$ \\
$(0.021)$ \\
\end{tabular} & $\begin{array}{l}-0.041^{* * *} \\
(0.015) \\
\end{array}$ & $\begin{array}{l}-0.001 \\
(0.001) \\
\end{array}$ \\
\hline Group size & $\begin{array}{l}-0.009^{* * * *} \\
(0.0001)\end{array}$ & & $\begin{array}{l}-0.016^{* * * *} \\
(0.001)\end{array}$ & $\begin{array}{l}-0.008^{* * * *} \\
(0.0001)\end{array}$ & & $\begin{array}{l}-0.015^{* * * *} \\
(0.001) \\
\end{array}$ \\
\hline Days & \begin{tabular}{|l|l}
$-0.0003^{* * * *}$ \\
$(0.0001)$
\end{tabular} & & \begin{tabular}{|l|l|}
$\begin{array}{l}0.0001^{* * * *} \\
(0.00001)\end{array}$ \\
\end{tabular} & $\begin{array}{l}-0.00004 \\
(0.0001)\end{array}$ & & \begin{tabular}{|l}
$\begin{array}{l}0.00001^{* *} \\
(0.00001)\end{array}$ \\
\end{tabular} \\
\hline Constant & \begin{tabular}{|l|}
$-6.938^{* * * *}$ \\
$(0.193)$ \\
\end{tabular} & \begin{tabular}{|l}
$-5.627^{* * * *}$ \\
$(0.184)$ \\
\end{tabular} & $\begin{array}{l}-5.323^{* * * *} \\
(0.092) \\
\end{array}$ & \begin{tabular}{|l|}
$-5.693^{* * * *}$ \\
$(0.254)$ \\
\end{tabular} & $\begin{array}{l}-4.995^{* * * *} \\
(0.220) \\
\end{array}$ & \begin{tabular}{|l|}
$-5 \cdot 384^{* * * *}$ \\
$(0.117)$ \\
\end{tabular} \\
\hline Observations & 4,696 & 4,686 & 4,696 & 3,121 & 3,121 & 3,121 \\
\hline $\mathrm{R}^{2} / \mathrm{R}^{2}$ marginal & 0.734 & 0.020 & 0.84 & 0.649 & 0.041 & 0.84 \\
\hline Adjusted R ${ }^{2}$ & 0.734 & & & 0.648 & & \\
\hline Log Likelihood & & 29,66 & 2,348 & & 19,44 & $2,497.491$ \\
\hline Residual Std. Error & $\begin{array}{l}1.175 \\
(\mathrm{df}=4686)\end{array}$ & & & $\begin{array}{l}1.326 \\
(\mathrm{df}=3111)\end{array}$ & & \\
\hline F Statistic & $\begin{array}{l}1,437^{* * * *} \\
(\mathrm{df}=9 ; 4686)\end{array}$ & & & $\begin{array}{l}638^{* * * *} \\
(\mathrm{df}=9 ; 111)\end{array}$ & & \\
\hline
\end{tabular}

Table 6. Regression Results.

The latter is captured by the openness metric. Open users keep the community alive, and engage in prolonged discussions, i.e. they contribute extensively to each thread (Cetto et al. 2018). They are of central importance to the community and their continuous engagement focuses on small groups, where they facilitate reciprocal interactions. This continuity of reciprocity leads to the formation of strong relationships, which are essential for social acceptance into the group (Bauer and Erdogan 2011; Saks and Ashforth 1997). In data set 1, we see a rather strong significant effect of openness, which, though, does not repeat in data set 2.Proactive users are the origin of such extended discussions (Angeletou et al. 2011; Hacker et al. 2017; Viégas and Smith 2004). By facilitating new conversations and asking questions, they get to know the roles and responsibilities of the new hire's position (Major et al. 2006) and learn the expected behaviours (Bauer and Erdogan 2011). Their proactive "question asking" is positive for the socialisation outcomes (Bauer and Erdogan 2011). However, proactiveness does not show a significant effect on the socialisation in our analysis. We find no association between activity and successful socialisation outcomes either. A reason can be that users with low activity have a low number of posts, which makes data scarce and the analysis difficult.

Similar to extraversion, relationship-building is negatively associated with the socialisation outcomes, which seems counterintuitive at first. While a high value indicates users, who are broadly connected over the whole network, for social integration, a focus on small groups and intense relationships is beneficial to build cohesion. Well-connected users are characterized as "key value adding users" (Berger et al. 2014) or very influential (Smith et al. 2009). However, for integration into a social group, this may be hindering, as such a person still needs to adapt to the social norms and shared behaviours to fit his new role (Leidner et al. 2010). Contrary to our hypothesis, feedback-seeking is negatively associated with the socialisation outcome in our models. We operationalise feedback-seeking as likes and mentions received. Because a like is not sufficient to form reciprocal relationships, it is important that a user receives written feedback. In contrast to likes, written replies are engaging with the content and would better form the basis for reciprocal interactions, leading to cohesion, trust and 
successful socialisation outcomes (Maznevski and Chudoba 2000). Information-seeking corresponds to the above-mentioned situation and measures the written replies a user received. Like argued, reciprocal interactions are the basis for formation of social relationships, leading to trust and cohesion in teams (Maznevski and Chudoba 2000). The results for data set 1 show that informationseeking is positively associated with successful socialisation outcomes.

Our model does not support the effect of the number of days a user is member in a group. A longitudinal study, which takes into account the dynamics of social interactions, may elucidate this factor in more detail. The group size has a significant negative effect on the social integration of a user. As a group gets bigger, it gets more difficult to foster relationships and be close with everyone in the group.

The differences between the two data sets are not easily explainable. We intended to compare the two data sets and find significant effects that recur. For extraversion, feedback-seeking, and group size, the results are consistent and significant. Other metrics are significant either for data set 1 or data set 2. Besides potential weaknesses in the operationalisation or data biases, the organizations may have different ESN usage policies or work cultures in place, which encourages or hinders certain behaviours. More data about the organizations and the related data sets would definitely allow further in-depth analyses. However, with our approach we originally find first results just from a snapshot of metacommunication data.

\section{Conclusion}

We selected user behaviours from the literature and performed various regression analyses to determine the effects of behaviour metrics on the integration of users into groups in enterprise social networks.

Utilising meta-communication data exclusively enables analyses where content data is unavailable, but provides only a limited lens for the analysis of complex socialisation processes. Several authors mention that a pure social network analysis is insufficient, because it misses the context (Rowe et al. 2013) and the organisational factors (Kuegler et al. 2015), which influence the outcomes of the socialisation process. Operationalisation of social factors is challenging and a different operationalisation may change the results of our analysis. Future research can benefit from a mixed-method approach, combining the social network analysis with qualitative insights, to validate the findings and provide a deeper understanding. Another prospect to validate the findings would be to gather more data on the users' personality traits and compare the results with the user behaviours.

The socialisation process depends not only on the user, but also on the group. Instead of controlling for the group size and using a random intercept on the group level, a more sophisticated approach would yield results that are more precise. For future research, we plan to gather more data on the media and group level to get a clearer picture on how the interdependence of user behaviour, group type and the used communication medium affects the outcomes of the socialisation process. Besides improving understanding of the process, we aim to improve the prediction accuracy and robustness of the model, which is especially helpful for practitioners as they are rather interested in accurate prediction than inference. To cope with the current lack of accuracy, the dynamics of the social network and effects beyond linear relationships, we plan to perform random-forest prediction or use neural networks. We have already performed preliminary unsupervised classification of group types in ESN and are looking to incorporate the results into our research on the socialisation process. Practitioners can use accurate prediction models to take deliberate management actions regarding the socialisation process. In a turbulent multi-project environment, management has to decide where to put new hires, and the insights on the socialisation process can inform staffing decisions. Especially if teams are quickly assembled, having decision support on the user-group integration is valuable to achieve effective team compositions.

\section{References}

Aboelmaged, M. G. 2018. 'Knowledge Sharing through Enterprise Social Network (ESN) Systems: Motivational Drivers and Their Impact on Employees' Productivity', Journal of Knowledge Management (22:2), pp. 362-383.

Angeletou, S., Rowe, M., and Alani, H. 2011. 'Modelling and Analysis of User Behaviour in Online Communities', in International SemanticWeb Conference (ISWC) (Vol. 10), pp. 35-50.

Bates, D., Maechler, M., Bolker, B., Walker, S., Christensen, R. H. B., Singmann, H., Dai, B., and Eigen, C. 2017. 'Lme4: Fitting Linear Mixed-Effects Models Using Lme4', Journal of Statistical Software (67:1), pp. 1-113. 
Bauer, T. N., and Erdogan, B. 2011. 'Organizational Socialization: The Effective Onboarding of New Employees.', in APA Handbook of Industrial and Organizational Psychology, Vol 3: Maintaining, Expanding, and Contracting the Organization., S. Zedeck (ed.), Washington: American Psychological Association, pp. 51-64.

Beck, R., Pahlke, I., and Seebach, C. 2014. 'Knowledge Exchange and Symbolic Action in Social MediaEnabled Electronic Networks of Practice: A Multilevel Perspective on Knowledge Seekers and Contributors', MIS Quarterly, pp. 1245-1270.

Berger, K., Klier, J., Klier, M., and Richter, A. 2014. 'Who Is Key...? Characterizing Value Adding Users in Enterprise Social Networks', in 22nd European Conference on Information Systems (ECIS) (Vol. Track 21).

Bergiel, B. J., Bergiel, E. B., and Balsmeier, P. W. 2008. 'Nature of Virtual Teams: A Summary of Their Advantages and Disadvantages', Management Research News (31:2), pp. 99-110.

Cetto, A., Klier, M., Richter, A., and Zolitschka, J. F. 2018. “'Thanks for Sharing”-Identifying Users' Roles Based on Knowledge Contribution in Enterprise Social Networks', Computer Networks (135), Elsevier B.V., pp. 275-288.

Chui, M., Manyika, J., Bughin, J., Dobbs, R., Roxburgh, C., Sarrazin, H., Sands, G., and Westergren, M. 2012. 'The Social Economy: Unlocking Value and Productivity through Social Technologies', McKinsey Global Institute (July), pp. 1-18.

Cribari-Neto, F., and Zeileis, A. 2009. 'Beta Regression in R', Research Report Series / Department of Statistics and Mathematics (Vol. 98), Vienna.

Cross, R., and Prusak, L. 2002. 'Organizations Go - or Stop Waiter', Harvard Business Review (January).

Duhigg, C. 2016. 'What Google Learned From Its Quest to Build the Perfect Team', The New York Times Magazine. (https://www.nytimes.com/2016/02/28/magazine/what-google-learned-from-itsquest-to-build-the-perfect-team.html).

Ellison, N. B., Gibbs, J. L., and Weber, M. S. 2015. 'The Use of Enterprise Social Network Sites for Knowledge Sharing in Distributed Organizations', American Behavioral Scientist (59:1), pp. 103123.

Ferrari, S. L. P., and Cribari-Neto, F. 2004. 'Beta Regression for Modelling Rates and Proportions', Journal of Applied Statistics (31:7), pp. 799-815.

Gleave, E., Welser, H. T., Lento, T. M., and Smith, M. A. 2009. 'A Conceptual and Operational Definition of "Social Role" in Online Community', in 42nd Hawaii International Conference on System Sciences (HICSS), pp. 1-11.

Gonzalez, E., Leidner, D., Riemenschneider, C., and Koch, H. 2013. 'The Impact of Internal Social Media Usage on Organization Socialization and Commitment', in 34th International Conference on Information Systems (ICIS), pp. 1-18.

Hacker, J., Riemer, K., and Bernsmann, R. 2017. 'Discovering Knowledge Actor Roles in Enterprise Social Networks - a Case Study in a Professional Services Firm', in Social Knowledge Management in Action: Applications and Challenges, R. Helms, F. Darses, R. Dieng, C. Simone, and M. Zackland (eds.), Springer, pp. 125-146.

Hansen, D. L., Shneiderman, B., and Smith, M. 2010. 'Visualizing Threaded Conversation Networks: Mining Message Boards and Email Lists for Actionable Insights', in International Conference on Active Media Technology, pp. 47-62.

Helms, R., and Buijsrogge, K. 2006. 'Application of Knowledge Network Analysis to Identify Knowledge Sharing Bottlenecks at an Engineering Firm', in Proceedings of the Fourteenth European Conference on Information Systems.

Holtzblatt, L., Drury, Jill, L., Weiss, D., Damianos, L. E., and Cuomo, D. 2013. 'Evaluating the Uses and Benefits of an Enterprise Social Media Platform', Journal of Social Media for Organizations (1:1), pp. 1-21.

Kammeyer-Mueller, J. D., and Wanberg, C. R. 2003. 'Unwrapping the Organizational Entry Process: Disentangling Multiple Antecedents and Their Pathways to Adjustment.', Journal of Applied Psychology (88:5), pp. 779-794.

Kuegler, M., Smolnik, S., and Kane, G. 2015. 'What's in IT for Employees? Understanding the Relationship between Use and Performance in Enterprise Social Software', The Journal of Strategic Information Systems (24:2), pp. 90-112.

Leidner, D., Koch, H., and Gonzalez, E. 2010. 'Assimilating Generation Y IT New Hires into USAA's 
Workforce: The Role Of An Enterprise 2.o System', MIS Quarterly Executive (9:4).

Leon, R.-D., Rodríguez-Rodríguez, R., Gómez-Gasquet, P., and Mula, J. 2017. 'Social Network Analysis: A Tool for Evaluating and Predicting Future Knowledge Flows from an Insurance Organization', Technological Forecasting and Social Change (114), pp. 103-118.

Major, D. A., Turner, J. E., and Fletcher, T. D. 2006. 'Linking Proactive Personality and the Big Five to Motivation to Learn and Development Activity', Journal of Applied Psychology (91:4), pp. 927935 .

Mäntymäki, M., and Riemer, K. 2016. 'Enterprise Social Networking: A Knowledge Management Perspective', International Journal of Information Management (36:6), pp. 1042-1052.

Maznevski, M. L., and Chudoba, K. M. 2000. 'Bridging Space Over Time: Global Virtual Team Dynamics and Effectiveness', Organization Science (11:5), INFORMS, pp. 473-492.

Nahapiet, J., and Ghoshal, S. 1998. 'Social Capital, Intellectual Capital, and the Organizational Advantage', The Academy of Management Review (23:2), pp. 242-266.

Oh, H., Chung, M., and Labianca, G. 2004. 'Group Social Capital and Group Effectiveness: The Role of Informal Socializing Ties', Academy of Management Journal (47:6), pp. 860-875.

Parise, S., Cross, R., and Davenport, T. H. 2006. 'Strategies for Preventing a Knowledge-Loss Crisis', MIT Sloan Management Review.

Powell, A., Piccoli, G., and Ives, B. 2004. 'Virtual Teams: A Review of Current Literature and Directions for Future Research', ACM SIGMIS Database (35:1), pp. 6-36.

Richter, A., and Riemer, K. 2013. 'Malleable End-User Software', Business and Information Systems Engineering (5:3), pp. 195-197.

Riemer, K., Finke, J., and Hovorka, D. S. 2015. 'Bridging or Bonding : Do Individuals Gain Social Capital from Participation in Enterprise Social Networks?', 36th International Conference on Information Systems (ICIS), pp. 1-20.

Riemer, K., Stieglitz, S., and Meske, C. 2015. 'From Top to Bottom: Investigating the Changing Role of Hierarchy in Enterprise Social Networks', Business and Information Systems Engineering (57:3), pp. 197-212.

Rowe, M., Fernandez, M., Angeletou, S., and Alani, H. 2013. 'Community Analysis through Semantic Rules and Role Composition Derivation', Journal of Web Semantics (18), pp. 31-47.

Saks, A. M., and Ashforth, B. E. 1997. 'Organizational Socialization: Making Sense of the Past and Present as a Prologue for the Future', Journal of Vocational Behavior (51:2), pp. 234-279.

Smith, M., Hansen, D. L., and Gleave, E. 2009. 'Analyzing Enterprise Social Media Networks', in International Conference on Computational Science and Engineering (Vol. 4), pp. 705-710.

Stieglitz, S., Meske, C., Ross, B., and Mirbabaie, M. 2018. 'Going Back in Time to Predict the Future The Complex Role of the Data Collection Period in Social Media Analytics', Information Systems Frontiers.

Stieglitz, S., Mirbabaie, M., and Milde, M. 2018. 'Social Positions and Collective Sense-Making in Crisis Communication', International Journal of Human-Computer Interaction.

Trier, M., and Richter, A. 2015. 'The Deep Structure of Organizational Online Networking - an ActorOriented Case Study', Information Systems Journal (25:5), pp. 465-488.

Viégas, F. B., and Smith, M. 2004. 'Visualizing the Activity of Individuals in Conversational Cyberspaces', in 37th Hawaii International Conference on System Sciences (HICSS), pp. 1-10.

Wehner, B., Ritter, C., and Leist, S. 2017. 'Enterprise Social Networks: A Literature Review and Research Agenda', Computer Networks (114), pp. 125-142.

Willyerd, K. 2012. 'Social Tools Can Improve Employee Onboarding', Harvard Business Review. (https://hbr.org/2012/12/social-tools-can-improve-e, accessed February 6, 2018).

Acknowledgement: Tobias Kroll has received a funded PhD scholarship from the Foundation of German Business.

Copyright: (C) 2018 Joschka Hüllmann and Tobias Kroll. This is an open-access article distributed under the terms of the Creative Commons Attribution-NonCommercial 3.0 Australia License, which permits non-commercial use, distribution, and reproduction in any medium, provided the original author and ACIS are credited. 